Letrônica, Porto Alegre, v. 7, n. 2, p. 695-712, jul./dez., 2014

\title{
MONOTONGAÇÃO DE DITONGOS ORAIS DECRESCENTES NA ESCRITA DE CRIANÇAS DE SÉRIES INICIAIS
}

\section{MONOPHTHONGIZATION OF ORAL FALLING DIPHTHONGS IN THE WRITING OF CHILDREN IN INITIAL SCHOOL YEARS}

\author{
Taíse Simioni* \\ Éder Lupe Rodrigues ${ }^{* *}$
}

\begin{abstract}
Resumo: A ocorrência de monotongação de ditongos decrescentes na fala é fato bastante conhecido. Alguns estudiosos têm se dedicado a observar como esse fenômeno pode se manifestar na escrita, e este trabalho se enquadra nesta vertente. Portanto, o objetivo deste trabalho é realizar uma pesquisa referente à ocorrência de monotongação em ditongos orais decrescentes na escrita de alunos das séries iniciais do Ensino Fundamental. São objeto de análise os ditongos [aj] e [ej], como nas palavras "caixa" e "queijo", que podem ser escritas "caxa" e "quejo", respectivamente. Participaram da pesquisa quarenta e dois alunos, divididos entre o 3ํㅜ o 4ํ e o 5o ano de uma escola pública do município de Bagé (RS). A coleta de dados foi feita a partir de gravuras que representavam palavras com os ditongos sob análise. As gravuras eram mostradas e os alunos escreviam as palavras. Os resultados indicaram que a taxa geral de monotongação na escrita é pequena e que o ditongo [aj] apresenta um pouco menos de apagamento do glide do que o ditongo [ej]. Além disso, no que diz respeito aos condicionantes linguísticos, foi possível perceber que o tepe favorece a ocorrência da monotongação. Sobre os condicionantes extralinguísticos, verificou-se que o sexo feminino favorece ligeiramente a monotongação e que houve um resultado inesperado no que diz respeito à escolaridade dos informantes, uma vez que o $4^{\circ}$ ano foi o que apresentou as maiores taxas de apagamento do glide. Este estudo aponta para a importância de os professores das séries iniciais terem os conhecimentos linguísticos necessários para realizar atividades pedagógicas bem fundamentadas nos casos em que a escrita revela padrões de variação que ocorrem na fala, como destaca Mollica (2000).
\end{abstract}

Palavras-chave: Monotongação; Ditongo Oral Decrescente; Oralidade/Escrita.

\begin{abstract}
The occurrence of monophthongization in falling diphthongs in the oral speech is a well-known fact. Some studious have been dedicated in observing how this phenomenon can appear in the writing, and this paper is according to them. Therefore the main aim of this paper is to carry out a field research that refers to the occurrence of monophthongization in falling diphthongs in the writing of students in initial years of Elementary School. The diphthongs [aj] and [ej] are the objects of this analysis, as in words "caixa" and "queijo" ("box" and "cheese") that can be written as "caxa" and "quejo", respectively, for instance. Forty-two students had participated in this field research, and they study in the 3rd, 4th and 5th years of a municipal school in the city of Bagé(RS - Brazil). The data were collected through pictures that represent words that contain the studied diphthongs. The pictures were showed to the students, and they should write the names of the represented objects.
\end{abstract}

\footnotetext{
* Professora Adjunta do Curso de Licenciatura em Letras da Universidade Federal do Pampa (Campus Bagé).

${ }^{* *}$ Graduando do Curso de Licenciatura em Letras da Universidade Federal do Pampa (Campus Bagé).
} 
The results have indicated that the rate of monophthongization in the writing is low, and the diphthong [aj] presents a little less glide deletion than the diphthong [ej]. Furthermore, about the linguistic conditioners, it was possible to observe that the tap favors the occurrence of monophthongization. About the extralinguistic conditioners, it was verified that girls lightly favors the monophthongization, and an unexpected result was obtained in relation with the educational level of the informants, once the 4th year presented the highest rates of glide deletion. This study highlights the importance of teachers from initial grades to have the necessary linguistic knowledge to carry out a well-founded pedagogic intervention in cases in which the writing reveals patterns of variation that occur in the speech, as pointed by Mollica (2000).

Keywords: Monophthongization; Oral Falling Diphthong; Orality/Writing.

\section{Introdução}

O fenômeno da monotongação de ditongos orais decrescentes (como a realização "caxa" para "caixa" ou "pexe" para "peixe) é bastante conhecido e discutido na literatura. Segundo Paiva (1996a), verifica-se a ocorrência deste processo ao longo de toda a história do português. Ainda conforme a autora, esta tendência a transformar ditongos em vogais simples já era verificada no latim vulgar. Há, portanto, muitos trabalhos que tomam a monotongação na fala como objeto de análise. Citamos como exemplo Paiva (1996a, 1996b) e Amaral (2005).

Ocorre que a monotongação pode ser refletida na escrita, como atestam os trabalhos de Mollica (2000), Hora e Ribeiro (2006), Ilha, Lara e Córdoba (2012) e Lima Henrique e Hora (2013), para citar alguns. Tais pesquisas buscam verificar o que pode estar condicionando a monotongação na escrita de alunos de séries iniciais. É possível encontrar, também, trabalhos que buscam correlacionar a variação na fala com a variação na escrita, como Amaral e Gonçalves (2013).

Mollica (2000) mostra que a instrução explícita sobre a relação entre a escrita e a monotongação que pode ocorrer na fala traz resultados positivos para o processo de aquisição da escrita ${ }^{1}$. A autora destaca a importância das pesquisas realizadas no âmbito da variação linguística, uma vez que seus resultados se tornam subsídios para o ensino da língua portuguesa. Hora e Ribeiro (2006) apontam nesta mesma direção ao afirmarem que

\footnotetext{
${ }^{1}$ Cabe destacar que os resultados a que a autora chega apontam para a eficácia da instrução explícita apenas a partir da $2^{\text {a }}$ série (ou, atualmente, $3^{\circ}$ ano). Mollica conclui que os dois anos iniciais "são momentos em que o alfabetizando está assimilando ainda a relação fonema/grafema, processo suficientemente complexo para introduzir-se mais informação sobre fala/escrita" (MOLLICA, 2000, p. 79).
} 
o reconhecimento da variação linguística como sendo inerente à linguagem por parte do professor que atua no nível de ensino fundamental poderá contribuir para a compreensão das diferentes formas empregadas pelos alunos, principalmente nos textos escritos que acabam espelhando quase sempre a fala (HORA; RIBEIRO, 2006, p. 216).

É neste contexto que se insere a presente pesquisa, que tem por objetivo investigar a monotongação de [ej] e [aj] na escrita de crianças que estudam no $3^{3}$, no $4^{\circ}$ o e no 5ํa anos de uma escola pública do município de Bagé (RS). Cabe explicar aqui por que o ditongo [ow] não foi incluído na análise.

Conforme mostram os estudos sobre a monotongação na fala, são três os ditongos em que o processo se mostra mais efetivo: [aj], [ej] e [ow]. Apenas os dois primeiros, conforme foi afirmado anteriormente, serão objeto de análise em nossa pesquisa. Motiva esta decisão o fato de que a monotongação em [ow] se mostra um processo diferente daquele que ocorre com os demais ditongos, como explicitam Paiva (1996a, p. 222) e Mollica (2000, p. 59). Como esclarecem as autoras, a monotongação de [ow] é mais ampla (não parece ser condicionada por variáveis linguísticas, por exemplo), sendo um fenômeno praticamente categórico. Já a supressão do glide anterior ainda se encontra fortemente influenciada por condicionantes linguísticos, como a consoante seguinte, por exemplo.

Tendo em vista que um de nossos objetivos, como será possível verificar adiante, é analisar a influência do contexto seguinte na ocorrência da monotongação na escrita, optamos por excluir o ditongo [ow] que, em conformidade com o que foi explicitado logo acima, não manifesta o condicionamento do contexto seguinte para sua monotongação, uma vez que esta mudança se encontra praticamente implementada na fala do português brasileiro (PB).Temos ciência de que, embora a monotongação de [ow] seja praticamente categórica na fala, sua monotongação não o é na escrita, como revelam alguns estudos que analisam a manifestação escrita deste ditongo. Entretanto, por se tratar de dois processos distintos, como esclarecem Paiva (1996a) e Mollica (2000), optamos por nos restringir aos ditongos que manifestam a atuação de condicionantes estruturais na sua realização oral.

Cabe mencionar que, entre as variáveis extralinguísticas a serem analisadas, estão a escolaridade e o sexo dos informantes. Tais variáveis foram incluídas pois há na literatura indícios de que elas exercem influência no fenômeno que estamos analisando. 
Interessa-nos, então, verificar como tais aspectos extralinguísticos se comportam na análise a que nos dedicamos.

0 artigo está organizado como segue. Em um primeiro momento, exporemos algumas questões teóricas que estão envolvidas na discussão sobre os ditongos. $\mathrm{Na}$ sequência, será explicitada a metodologia adotada. Depois, apresentamos a análise dos resultados. Por fim, encontram-se as considerações finais.

\section{0 ditongo decrescente na literatura}

Esta seção tem por objetivo discutir a estrutura de uma sílaba com ditongo decrescente. Não será objeto de análise o ditongo crescente².

Em (1), encontramos os padrões silábicos do PB apresentados por Collischonn (1997, p. 77). Em (1a), estão as sílabas abertas; em (1b), as sílabas fechadas por uma consoante; e, em (1c), as sílabas fechadas por duas consoantes.

(1)

$\begin{array}{lll}\text { (a) V } & \text { é, aberto } \\ & \text { CV } & \text { cá, palito } \\ \text { CCV } & \text { pré, allito }\end{array}$

(b) CVC mar, peste

VC ar, ontem

CCVC três, grande

(c) CVCC perspicaz

CCVCC transpor, trens

VCC instante

Segundo a autora, além destes, há também os padrões silábicos que incluem os ditongos, como vemos em (2) (COLLISCHONN, 1997, p. 77). Em (2a), estão os padrões em que os ditongos encontram-se no final absoluto da sílaba, e, em (2b), aparecem os padrões em que os ditongos são seguidos por uma consoante.

${ }^{2}$ Especificamente sobre o ditongo crescente, sugerimos a leitura de Rosenthall (1997), Cabré e Prieto (2004) e Simioni (2008). 
(2)

$\begin{array}{lll}\text { (a) CVV } & \text { pai, reino } \\ & \text { CCVV } & \text { grau, frei } \\ \text { VV } & \text { oito, aurora }\end{array}$

(b) CCVVC graus, claustro

CVVC mais, cáustico

VVC eis, austríaco

Tomando como referência os padrões apresentados em (2), discutiremos a posição que o glide do ditongo decrescente ocupa na estrutura silábica e observaremos os argumentos para que se defenda o glide como núcleo ou como coda silábica.

Câmara Jr. (1970) defende a ideia de que o glide do ditongo decrescente forma com a vogal precedente um núcleo complexo. Para o autor, justifica-se esta proposta em função de que o ditongo decrescente só pode ser seguido por um r fraco, como em Laura, eira e europeu, ao contrário do que ocorre com sílabas que seriam verdadeiramente terminadas em coda, como em guelra e Israel. 0 autor não utiliza a terminologia "coda" e "núcleo complexo", mas procura distinguir um glide (vogal assilábica, na verdade) que se comporta como consoante de um glide que se comporta como vogal, preferindo a segunda opção,no caso dos ditongos decrescentes. Como veremos adiante, é possível contestar este argumento, como o faz Collischonn (1997).

Collischonn (1997) e Bisol (1999), por outro lado, defendem a hipótese de que o glide do ditongo decrescente constitui uma coda silábica. Ambas as autoras utilizam-se do mesmo argumento para tal: o fato de que glides do ditongo decrescente não coocorrem com os outros segmentos permitidos em coda em PB - a nasal e as líquidas $r$ e $l$, como mostram os exemplos em (3), retirados de Collischonn(1997, p. 81) ${ }^{3}$. Os exemplos em (3d) mostram que estes glides co-ocorrem com $s$, mas isto também acontece com os demais segmentos permitidos em coda, como é possível observar nos exemplos monstro, perspectiva e solstício ${ }^{4}$. Para as autoras, isto é evidência de que o glide do ditongo decrescente estão cupando a mesma posição dos demais segmentos permitidos em coda. Se o glide ocupasse a posição de núcleo não haveria nada, em princípio, que impediria a co-ocorrência entre ditongo decrescente e coda.

\footnotetext{
${ }^{3}$ Cabe mencionar que Massini-Cagliari (2003) também se utiliza deste critério para defender a hipótese de que o glide do ditongo decrescente ocupa a posição de coda em português arcaico, em que, segundo mostra a autora, apenas os mesmos segmentos do estágio atual do PB são permitidos nesta posição silábica.

${ }^{4}$ Em palavras como estas, segundo Bisol (1999, p. 704), está sendo aplicada a Regra de Adjunção de /S/, a partir da qual se acrescenta /S/ a uma rima bem formada.
} 
(3)

(a) $\quad * \mathrm{Sa}[\mathrm{w}] \mathrm{l}$

*Ma[j]lson

*do[j]l

*E[w]ltaquio

(b) *ca[w]rtico

*A[j]rton

${ }^{*} \mathrm{Ja}[\mathrm{j}] \mathrm{r}$

*do[j]r

*E[w]rtáquio

*di[w]rno

(c) $\quad *$ ca[w]ntico

*a[j]nda

*do[j]n

*de[w]n

(d) cá[w]stico

$\mathrm{ca}[\mathrm{j}] \mathrm{s}$

do[j]s

$\mathrm{E}[\mathrm{w}]$ stáquio

Collischonn (1997) discute o argumento de Camara Jr. (1970), mencionado anteriormente, segundo o qual os glides do ditongo decrescente pertencem ao núcleo silábico uma vez que são seguidos por $r$ fraco, como em europeu, ao contrário do que acontece quando o $r$ segue uma consoante, como em guelra. Segundo Collischonn (1997), é possível analisar estes fatos a partir da perspectiva de que o $r$ forte intervocálico é constituído por uma sequência de dois $r$ fracos (proposta feita por Harris (1983) para o espanhol e por Lopez (1979) e Monaretto (1994) para o PB), sendo que um preencheria a coda de uma sílaba, e o outro, o ataque da sílaba seguinte. Assim, o glide do ditongo decrescente não pode ser seguido por um $r$ forte porque isto implica que o glide estaria co-ocorrendo com outro segmento em coda, o que não é possível, como acabamos de ver ${ }^{5}$. No caso de palavras como guelra e Israel, não haveria geminação do $r$, segundo Collischonn (1997). Para explicar a ocorrência de $r$ forte em palavras como estas,Collischonn (1997) lança mão de uma regra proposta por Harris (1983, p. 63), segundo a qual um $r$ fraco realiza-se como $r$ forte quando for antecedido por uma consoante na posição de rima.

\footnotetext{
${ }^{5} \mathrm{~A}$ autora traz como evidência para esta análise o fato, registrado em Harris (1983), de que não há palavras proparoxítonas com $r$ forte entre a penúltima e última vogal ( ${ }^{*}$ cáchorro, ${ }^{*}$ cígarro), o que demonstra que a penúltima sílaba é pesada, levando em consideração uma análise segundo a qual a coda contribui para a atribuição de peso em línguas como o espanhol e o português.
} 
Levando em consideração o argumento discutido em Collischonn (1997) e Bisol (1999), adotaremos neste trabalho a hipótese de que o glide do ditongo decrescente faz parte da coda silábica. Desta forma, a monotongação será interpretada por nós como o apagamento da coda silábica.Nesta perspectiva, a monotongação pode ser representada como em (4), conforme sugerem Hora e Ribeiro (2006, p. 214). Cabe mencionar que essa representação é feita com base na estrutura silábica proposta por Selkirk (1982), em que $\sigma$ representa a sílaba; A representa o ataque; $\mathrm{R}$ representa a rima; $\mathrm{N}$ representa $\mathrm{o}$ núcleo; e Cd representa a coda. Em (4), a palavra “caixa” está representada em sua forma ortográfica.

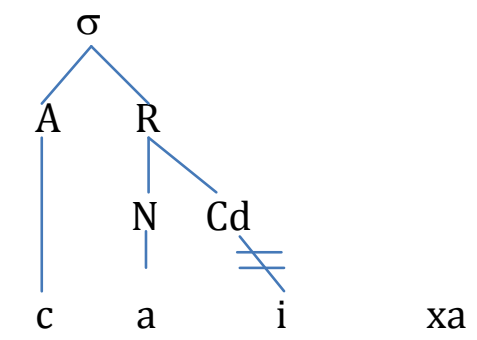

É possível perceber que o ditongo foi analisado aqui a partir do momento em que ele já está constituído como tal. Não discutiremos neste trabalho a formação do ditongo decrescente por entendermos que isto não afeta diretamente a análise a ser feita. Para uma proposta de descrição da formação do ditongo decrescente em português, sugerese a leitura de Bisol (1994) ${ }^{6}$.

\footnotetext{
${ }^{6}$ Segundo Bisol (1994), há os verdadeiros e os falsos ditongos. Nesta perspectiva, o objeto de análise do presente trabalho seriam os falsos ditongos, ou seja, aqueles que são passíveis de uma realização variável. Se nos comprometêssemos a assumir a proposta de Bisol (1994), não poderíamos denominar o processo sob análise de "monotongação", uma vez que, por esta proposta, o ditongo pode ou não se formar por espraiamento de traços, ou seja, a realização com uma vogal simples, como em "caxa" para "caixa", não resulta de apagamento do glide, mas sim da ausência do espraiamento. Amaral e Gonçalves (2013) sugerem que, inicialmente, os falantes interpretam os ditongos decrescentes variáveis como constituídos por apenas uma vogal na representação fonológica. Segundo as autoras, o processo de escolarização produziria modificações nesta representação. Como explicitamos acima, não nos ocuparemos aqui de aprofundar a discussão sobre a representação fonológica dos ditongos decrescentes sob análise.
} 


\section{Metodologia}

Conforme foi mencionado na introdução, nosso objetivo é verificar a ocorrência da monotongação de [ej] e [aj] na escrita de crianças em anos iniciais. Para tal, aplicouse um teste com crianças que estudam em uma escola pública da cidade de Bagé (RS). Participaram alunos de uma turma do $3^{\text {o }}$ (11 alunos), do $4^{\text {o }}$ (15 alunos) e do 5o (16 alunos) anos, totalizando 42 informantes. Não foram incluídos alunos dos $1^{\text {o }}$ e $2^{\text {o }}$ anos pela grande probabilidade de encontrarmos alunos não alfabetizados nesta etapa escolar, considerando que o teste foi aplicado antes da metade do ano letivo.

Cabe destacar que Bagé encontra-se na fronteira com o Uruguai, de maneira que a proximidade com um país de língua espanhola pode exercer influência sobre os resultados. Como explica Amaral (2005), "nesta língua, a maioria das palavras em que, no português, ocorre a variação, já foram monotongadas pelo processo evolutivo da língua" (AMARAL, 2005, p. 102). Desta forma, é possível supor que, no município de Bagé, a monotongação na escrita seja favorecida, uma vez que seus habitantes têm bastante contato com a língua espanhola falada e escrita. Em nosso trabalho, não poderemos comparar os resultados da monotongação em Bagé com outras regiões, uma vez que a metodologia empregada em outros trabalhos diverge da que empregamos. Entretanto, abre-se a possibilidade para que esta comparação possa ser feita em trabalhos futuros que empreguem a mesma metodologia.

Para a realização da coleta de dados foram selecionadas as oito palavras que são apresentadas em (5).

(5)

caixa

faixa

queijo

beijo

peixe

queixo

cadeira

mangueira

Além destas, fizeram parte do teste quatro palavras distratoras, ou seja, que não continham o objeto sob análise: "frutas", "livro", "celular" e "borboleta”. 
As doze palavras do teste (oito com o contexto para a monotongação e quatro distratoras) foram apresentadas aos alunos por meio de gravuras em uma ordem aleatória, através de um sorteio. Foi tomado cuidado para que as gravuras não pudessem gerar mais de uma interpretação. De fato, nenhum dos alunos escreveu uma palavra diferente da que esperávamos.

Como é possível observar nas palavras em (5), analisamos a atuação de um condicionante linguístico: o contexto seguinte ao ditongo decrescente. Para a escolha destes contextos, levou-se em consideração os segmentos que claramente favorecem a monotongação, conforme mostra a literatura sobre o assunto: no caso de [aj], []] em "caixa" e "faixa"; no caso de [ej], [3] em "queijo" e "beijo", [S] em "peixe" e "queixo" e [r] em "cadeira" e "mangueira". Desta forma, será possível verificar quais, dentre estes contextos, exercem um maior ou menor favorecimento para a monotongação.

A fim de não haver a possível interferência de fatores como tonicidade e constituição interna da palavra, todas as palavras apresentam o ditongo na sílaba tônica e na raiz7 . Embora pudesse ser interessante a inclusão de variáveis como tonicidade e constituição interna da palavra, uma vez que autores como Paiva (1996a) e Amaral (2005) mostram que estas questões podem interferir na realização da monotongação na fala, optamos por incluir mais de uma palavra com cada contexto seguinte ao invés de ampliar as variáveis analisadas. Se incluíssemos três variáveis linguísticas (contexto seguinte, tonicidade e constituição interna da palavra) e mantivéssemos o critério de haver duas palavras com cada contexto, seria necessária a aplicação de um teste com um número excessivo de palavras, o que o tornaria muito cansativo para crianças em fase inicial de escolarização.

Com relação a condicionantes extralinguísticos, temos por objetivo analisar a influência do sexo e da escolaridade na monotongação que ocorre na escrita. A distribuição dos alunos por sexo não foi equânime: havia dois meninos e nove meninas no terceiro ano; oito meninos e sete meninas no quarto ano; e cinco meninos e onze meninas no quinto ano. Isto totaliza 15 meninos e 27 meninas. A estratificação dos informantes pode ser observada no Quadro 1 abaixo.

\footnotetext{
${ }^{7}$ No caso de "mangueira", a gravura apresentada se refere ao objeto que serve para molhar as plantas, por exemplo. Não se trata da árvore que dá a manga como fruto.
} 
Quadro 1: Estratificação dos informantes

\begin{tabular}{|l|c|c|}
\hline Ano & Masculino & Feminino \\
\hline $3^{\mathbf{o}}$ ano & 2 & 9 \\
\hline $4^{\mathbf{o}}$ ano & 8 & 7 \\
\hline $5^{\mathbf{o}}$ ano & 5 & 11 \\
\hline
\end{tabular}

\section{Descrição e análise dos resultados}

Como nossa pesquisa contou com 42 informantes e cada um produziu oito dados, chegamos a um total de 336 dados. Destes, houve monotongação em 41 dados, o que significa um total de 12,20\% de monotongação, como é possível observar no Gráfico 1 abaixo.

Gráfico 1: Resultados gerais da monotongação

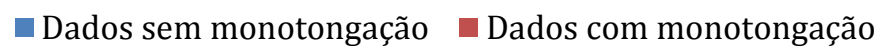

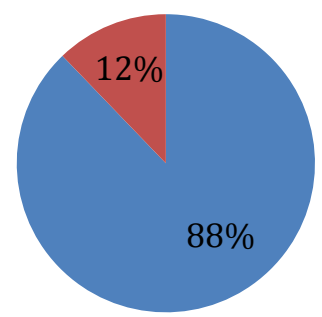

Como é possível verificar no Gráfico 2, na comparação entre o ditongo [aj] e o [ej], houve uma pequena preferência pela monotongação de [ej]. Dos 252 dados com [ej], houve monotongação em 32 (12,69\%), enquanto, dos 84 dados com [aj], ocorreu monotongação em 9 (10, 71\%). Embora a diferença seja pequena, cabe mencionar que este resultado vai ao encontro do que é possível encontrar em outros trabalhos sobre o tema. Hora e Ribeiro (2006) destacam que um resultado como este é esperado em função da maior saliência que existe em [aj] se comparado com [ej] ${ }^{8}$. A distância fonética entre [a] e [j] é maior do que aquela que existe entre [e] e [j]. Uma vez que há uma maior saliência do ditongo [aj], se comparado com [ej], é possível imaginar que haja um maior monitoramento na escrita de palavras que envolvem o primeiro ditongo.

${ }^{8}$ Hora e Ribeiro (2006) incluem na análise o ditongo [ow]. 
Gráfico 2: Resultados damonotongação de [aj] e [ej]

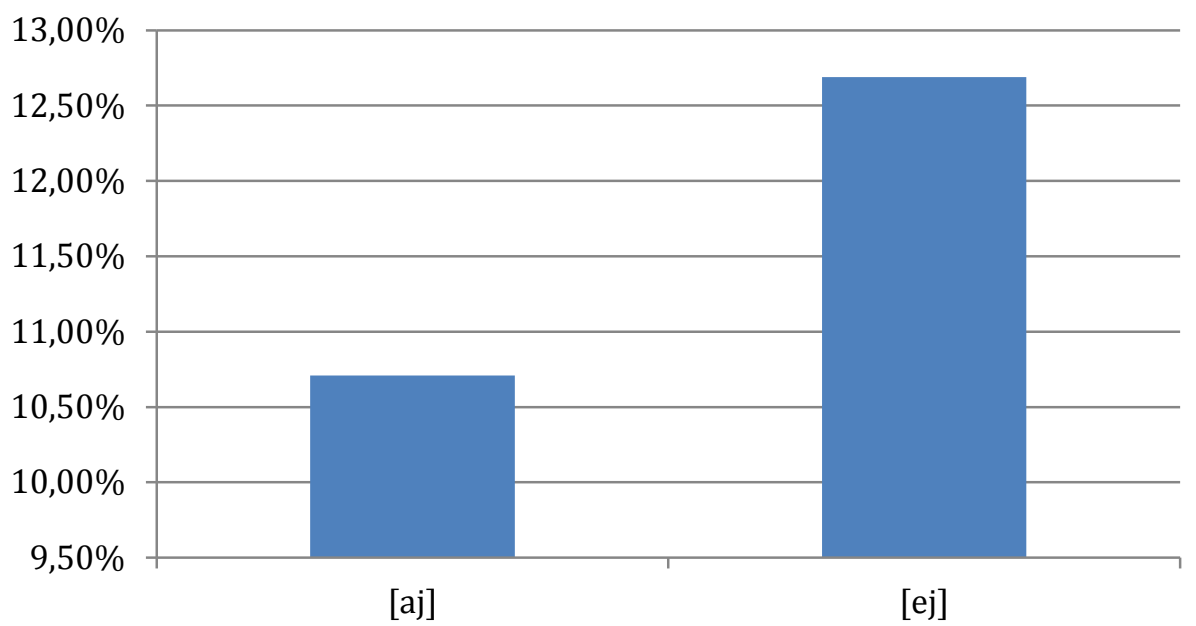

Verificaremos, agora, o comportamento da variável linguística sob análise - o contexto seguinte. Para esta análise, será incluído apenas o ditongo [ej], uma vez que, para o ditongo [aj], há apenas um contexto seguinte ([aj] diante de [J], como em "caixa"). Com esta variável, buscou-se comparar os resultados para os três contextos seguintes que claramente favorecem a monotongação de [ej]: [J], como em "peixe"; [3], como em "queijo"; e [r], como em "cadeira".

O Gráfico 3 mostra que, dos três contextos seguintes, [r] provoca mais monotongações: dos 84 dados com [r] como contexto seguinte, houve monotongação em 15 (17,85\%); enquanto o contexto seguinte [3] apresentou monotongação em 12 dos 84 dados (14,28\%); e o contexto seguinte [ [] mostrou monotongação em 5 dos 84 dados (5,95\%). Estes resultados poderiam apontar para uma tendência de que os segmentos vozeados favorecem a monotongação. É interessante observarmos que, no caso da monotongação de [aj], que, na fala, ocorre diante de [J], uma consoante surda, houve uma taxa de monotongação de 10,71\%, como mostramos acima. Esta taxa é menor do que aquelas encontradas para [r] e [3] no que diz respeito ao ditongo [ej], mas é maior do que a taxa apresentada para o mesmo contexto para [ej], o que, mais uma vez, pode destacar a influência da vogal [a] como desfavorecedora da monotongação. Estes resultados sugerem um olhar mais cuidadoso sobre a atuação do vozeamento do contexto seguinte em trabalhos futuros. 
Gráfico 3: Resultados da monotongação de [ej] em função do contexto seguinte

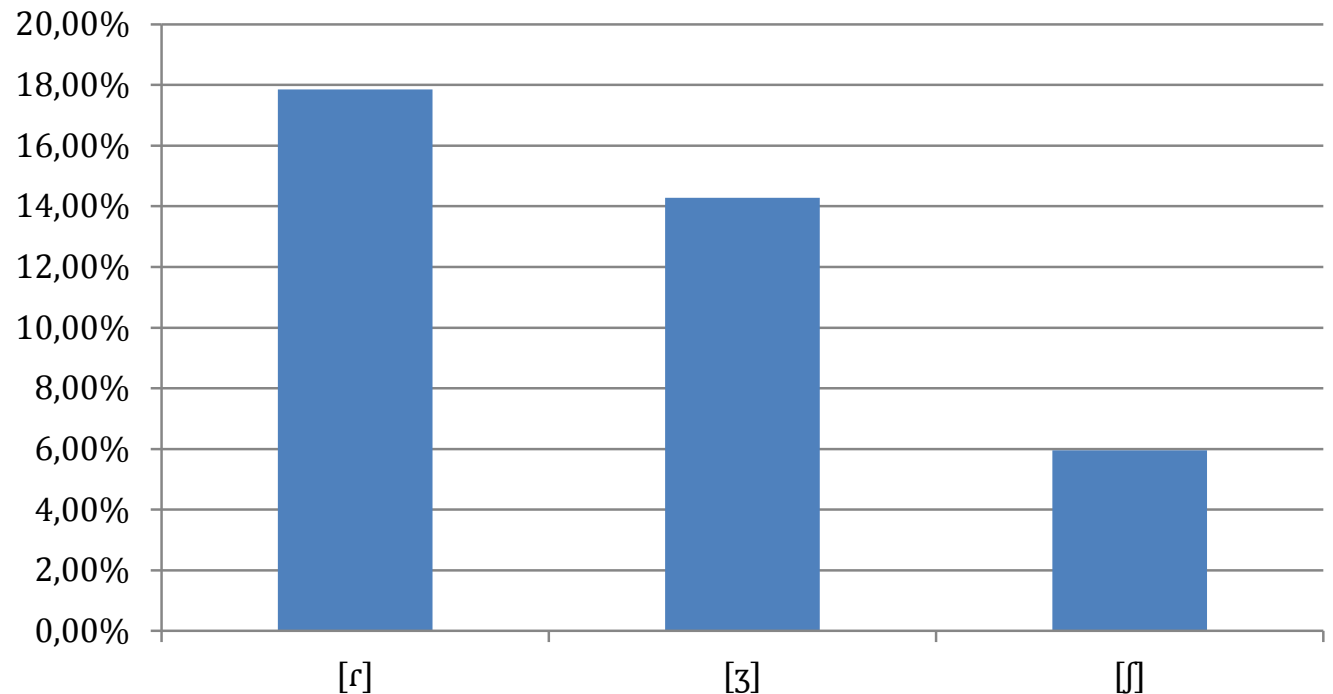

Mollica (2000) traz um resultado interessante sobre a influência do tepe como contexto seguinte ao ditongo sujeito à monotongação. Para sua análise, a autora dividiu os informantes em dois grupos: aqueles que recebem instrução explícita sobre a representação gráfica de alguns ditongos e aqueles que não recebem tal instrução. De acordo com Mollica, há uma clara diferença entre estes dois grupos no que se refere ao contexto seguinte [r]. Os alunos que recebem instrução explícita realizam muito menos monotongação neste contexto (principalmente no que corresponde atualmente para nós ao $3^{\mathrm{o}}$ ano). De acordo com a autora, isto ocorre porque o tepe é um "ambiente produtivo na fala e rapidamente entendido pelo aprendiz como contexto em que o i deve ser representado mesmo que [y] não seja realizado na fala"9 (MOLLICA, 2000, p. 73). Desta forma, o resultado acima poderia ser diferente se os alunos recebessem instruções explícitas sobre a relação entre a fala e a escrita no que diz respeito ao ditongo decrescente variável. Com isto chamamos a atenção, mais uma vez, sobre a importância de professores de anos iniciais terem este tipo de conhecimento, a fim de compreenderem o que está por trás das escritas não convencionais de seus alunos e proporem atividades que os auxiliem na superação de suas dificuldades.

A fim de aprofundar a discussão sobre o contexto seguinte, procedeu-se a uma análise por palavra, como pode ser visto no Gráfico 4. As palavras com ditongo diante de

\footnotetext{
${ }_{9}^{9}$ Paiva (1996a) e Amaral (2005), que analisam a fala, mostram que o tepe é o contexto que mais favorece a monotongação.
} 
[J] ("peixe" e "queixo") parecem ter apresentado um comportamento semelhante, no sentido de que nas duas as taxas de monotongação foram relativamente pequenas $(4,76 \%$ e 7,14\%, respectivamente), se comparadas com as taxas apresentadas para o tepe, por exemplo. No caso de [r], as duas palavras ("cadeira" e "mangueira") mostraram taxas elevadas de monotongação, quando comparadas com outras palavras (14,28\% e 21,42\%, respectivamente). Já o contexto seguinte [3] mostrou um comportamento inesperado. As duas palavras analisadas ("queijo" e "beijo") revelaram taxas de monotongação bastante distantes entre si $(23,80 \%$ e $4,76 \%$, respectivamente). Diante deste resultado, foram incluídas no Gráfico 4 as palavras com ditongo [aj] ("caixa" e "faixa"), que também mostraram comportamentos díspares entre si (0\% e 21,42\%, respectivamente).

Embora não estejamos falando aqui de um processo de mudança na escrita, esta tendência de mudança na fala é evidente (principalmente no caso do ditongo [ow]), conforme mostram estudos sobre o assunto. Desta forma, fica a dúvida sobre as duas perspectivas a partir das quais podemos analisar a mudança sonora: trata-se de um processo que segue a hipótese neogramática ou que se pauta pelos postulados da difusão lexical? A esse respeito, seria possível esperar comportamentos distintos na fala e na escrita? Não temos como responder a esta questão neste momento, mas os resultados apontam para a necessidade de um aprofundamento da questão.

Gráfico 4: Resultados da monotongação por palavra

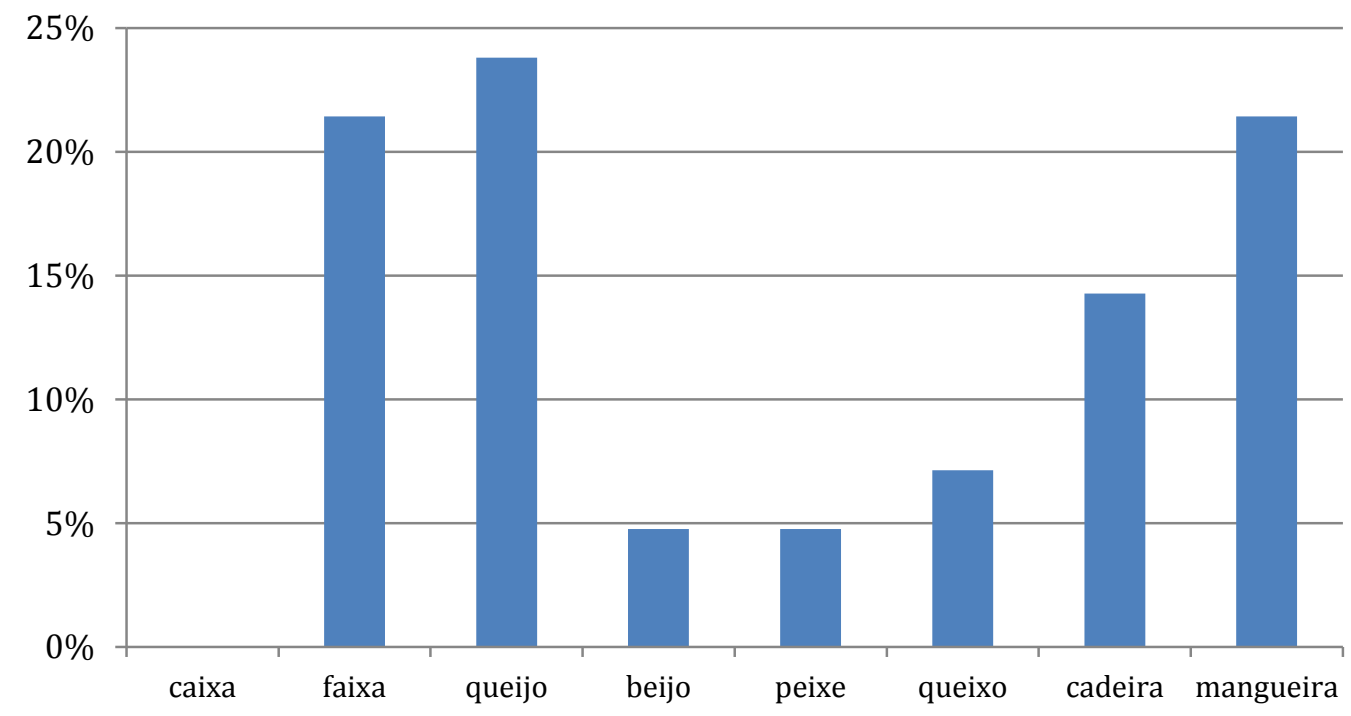


Passemos a analisar as variáveis extralinguísticas consideradas em nosso trabalho. A partir de agora, a monotongação de [aj] e [ej] são analisadas sempre em conjunto. 0 Gráfico 5 traz os resultados relativos ao sexo dos informantes. A monotongação entre as meninas foi um pouco maior do que aquela observada entre os meninos. Dos 216 dados produzidos pelas meninas, houve monotongação em 28 (12,96\%). Já entre os meninos, dos 120 dados produzidos, ocorreu monotongação em 13 $(10,83 \%)$.

Gráfico 5: Resultados da monotongação em função do sexo dos informantes

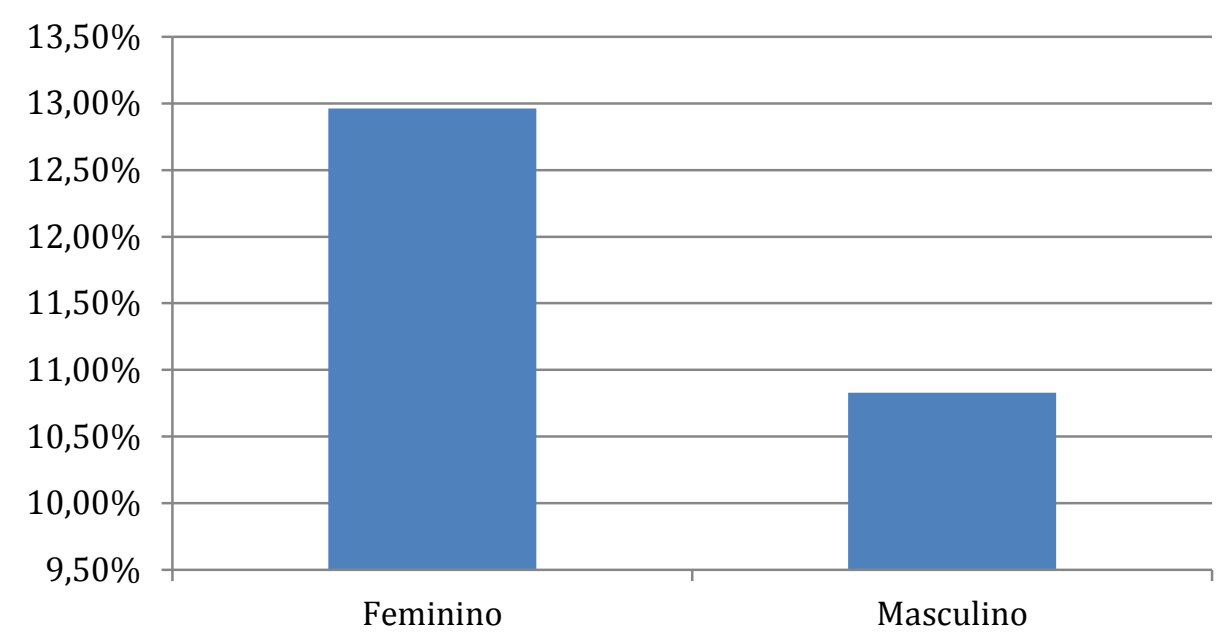

Este resultado contraria o esperado, uma vez que estudos como o de Hora e Ribeiro (2006) e Lima Henrique e Hora (2013), que analisaram a escrita, apontam para o sexo masculino como um favorecedor da monotongação. Amaral e Gonçalves (2013), que correlacionaram a variação na fala com a variação na escrita de ditongos decrescentes, também indicam uma presença mais acentuada do glide na realização oral e escrita de meninas. Segundo enfatizam Lima Henrique e Hora (2013), isto pode ocorrer pela tendência que as mulheres têm a um maior comprometimento com o padrão linguístico.

Como apontam alguns estudos variacionistas, se entre as variantes há uma prestigiada e outra estigmatizada, as mulheres tenderão a preferir a prestigiada ${ }^{10}$. Em função da pequena diferença observada entre o comportamento de meninos e meninas na monotongação sob análise, podemos pressupor que a ausência de um valor atribuído

\footnotetext{
10 Sobre a questão, sugerimos a leitura de Paiva (2010).
} 
a uma das variantes na fala tem reflexos na escrita também (por mais que, na escrita, haja claramente uma forma padrão e outra não-padrão). Sobre a fala, Paiva (1996b) mostra que o sexo não é relevante para a variação que ocorre nos ditongos decrescentes. De maneira mais ousada, poderíamos também levantar a hipótese de que, na sociedade brasileira, os papéis que homens e mulheres ocupam estão menos diferenciados, de maneira que isto se reflete em uma diminuição das diferenças de comportamento entre eles no que diz respeito aos fenômenos variáveis ${ }^{11}$. Obviamente, qualquer uma das alternativas de análise carece de um aprofundamento para que possa ser defendida.

Para finalizar, observaremos a influência da escolaridade na monotongação aqui analisada. 0 Gráfico 6 revela que os alunos do terceiro ano produzem a monotongação em 10 dos 88 dados produzidos (11,36\%). Entre os alunos do quarto ano, a monotongação aparece em 27 dos 120 dados produzidos (22,5\%). Já entre os alunos do quinto ano, a monotongação ocorre em 4 dos 128 dados produzidos $(3,12 \%)$.

Gráfico 6: Resultados da monotongação em função da escolaridade

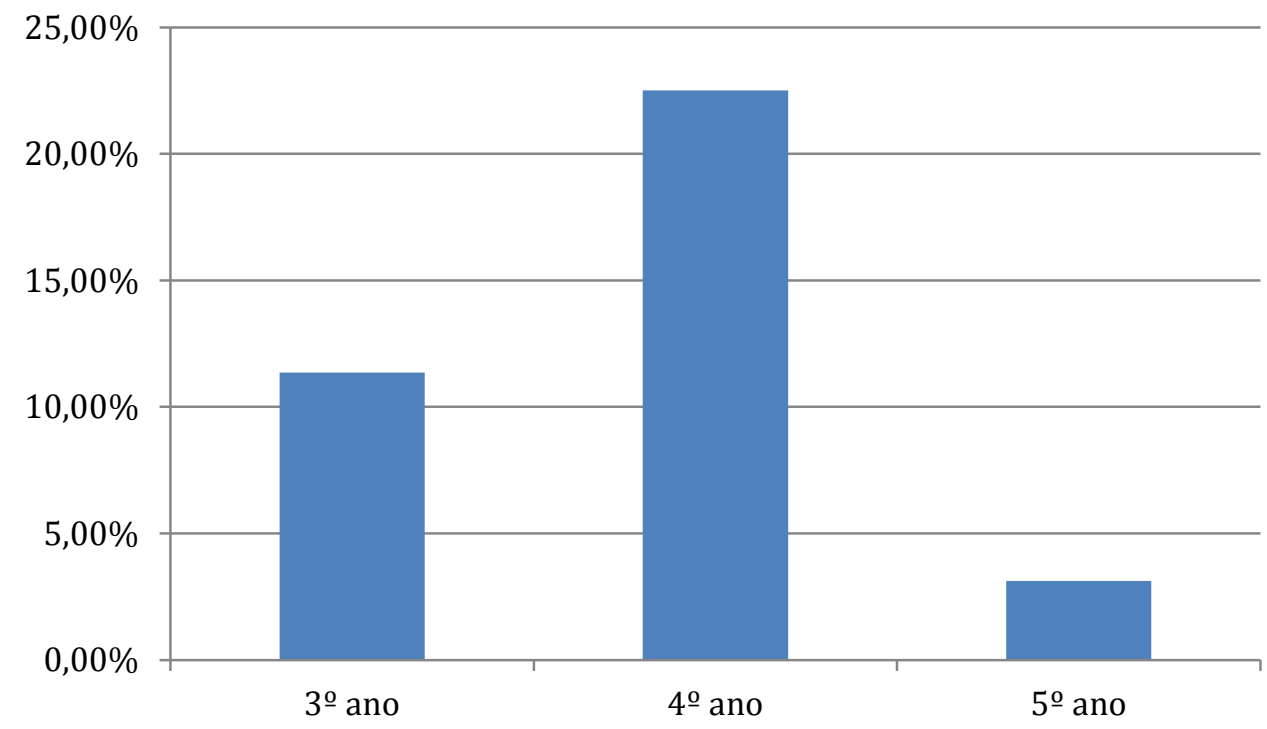

Estes resultados contrariam parcialmente nossa hipótese inicial, segundo a qual a monotongação diminuiria do $3^{\mathrm{o}}$ ao $5^{\mathrm{o}}$ ano de escolaridade. $04^{\mathrm{o}}$ ano demonstra um comportamento atípico, uma vez que houve um aumento significativo nas taxas de

\footnotetext{
${ }^{11}$ Uma outra opção de análise seria questionar se vale para crianças o que é dito a respeito de homens e mulheres e seu comportamento diante de fenômenos variáveis, no sentido de que o gênero social ainda está em construção nas crianças que participaram da pesquisa.
} 
monotongação quando comparadas com as do $3^{\circ}$ ano. Talvez a explicação para este resultado esteja no ambiente da sala de aula. Enquanto a sala do $3^{\circ}$ ano é repleta de estímulos visuais, com a presença de vários inputs escritos, a sala do $4^{0}$ ano tem as paredes cinzas e não há cartazes colados nelas. Sabemos que os alunos não têm contato com a escrita somente na sala de aula, mas sabemos também que este é um ambiente privilegiado para este contato, principalmente no caso de alunos de baixo poder aquisitivo. Desta forma, podemos supor, a partir das características físicas das salas de aula, que haja diferenças metodológicas entre as duas professoras responsáveis pelas turmas, no sentido que a do $3^{\circ}$ ano propicie aos alunos mais contato com textos escritos, o que é essencial nessa fase inicial de aprendizado da escrita.

\section{Considerações finais}

Este estudo investigou a monotongação de ditongos orais decrescentes na escrita de quarenta e dois alunos do $3^{\circ}$ ao $5^{\circ}$ ano de uma escola pública do município de Bagé (RS). Neste trabalho é possível perceber como os alunos transpõem para a escrita fenômenos variáveis que ocorrem na fala, evidenciando a importância de os professores de séries iniciais terem os conhecimentos linguísticos necessários para compreenderem as produções de seus alunos e adotarem estratégias bem fundamentadas para a superação das dificuldades que muitos aprendizes enfrentam.

No que diz respeito aos resultados obtidos, verificou-se que a taxa geral de monotongação na escrita foi pequena $(12,20 \%)$ e que o ditongo [ej] apresenta uma taxa de apagamento do glide um pouco superior à de [aj]. Foi possível, também, observar os condicionantes que influenciam a ocorrência do fenômeno. No que se refere ao contexto seguinte, destaca-se o [r] como segmento favorecedor da monotongação, embora a diferença de comportamento entre as palavras com o mesmo contexto seguinte nos leve a questionar como, de fato, esta variável linguística deve ser interpretada. Em relação ao sexo do informante, entre as meninas a monotongação foi ligeiramente maior. No que diz respeito à escolaridade, o $4^{\circ}$ ano, de uma maneira inesperada, foi o que apresentou $a$ maior taxa de apagamento do glide, o que pode trazer evidências para a relevância de um ambiente visualmente estimulante nos anos iniciais de escolarização. 
Para finalizar, destacamos a importância de o professor conhecer as variedades linguísticas de seus alunos. Mattos e Silva (2004) deixa isto muito claro quando afirma que

0 professor [...] terá de ser evidentemente muito bem preparado tanto na sua formação linguística - o que não ocorre hoje no Brasil - como na sua formação pedagógica geral, para entender essa complexa problemática que envolve a diversidade dialetal falada e a relativa homogeneidade que se apresenta na escrita (MATTOS e SILVA, 2004, p. 76).

\section{Referências}

AMARAL, Marisa Porto do. Ditongos variáveis no sul do Brasil. Letras de Hoje, v. 40, n. 3, p. 101-116, 2005.

AMARAL, Veronica S. do; GONÇALVES, Giovana F. Produções orais e escritas dos ditongos [aj], [ej] e [ow]: dados de São José do Norte/RS. Diadorim, v. 14, p. 127-154, 2013.

BISOL, Leda. Ditongos derivados. D.E.L.T.A., v. 10, n. Especial, p. 123-140, 1994.

. A sílaba e seus constituintes. In: NEVES, Maria Helena de Moura (Org.). Gramática do português falado. São Paulo: Humanitas / Campinas: Editora da UNICAMP, v. VII, 1999. p. 701-742.

CABRÉ, Teresa; PRIETO, Pilar. Prosodic and analogical effects in lexical glide formation in Catalan. Probus, n. 16, p. 113-150, 2004.

CAMARA JR., Joaquim Mattoso. Estrutura da língua portuguesa. Petrópolis: Vozes, 1970.

COLlisCHONN, Gisela. Análise prosódica da sílaba em português. 1997. 238f. Tese (Doutorado em Letras) -Pontifícia Universidade Católica do Rio Grande do Sul, Porto Alegre, 1997.

HARRIS, James W. Syllable Structure and Stress in Spanish: A Nonlinear Analysis. Cambridge, Mass.: MIT Press, 1983.

HORA, Dermeval da; RIBEIR0, Sílvia Renata. Monotongação de ditongos orais decrescentes: fala versus grafia. In: GORSKI, Edair Maria; COELHO, Izete Lehmkuhl (orgs.) Sociolingüística e ensino. Florianópolis: Ed. da UFSC, 2006. p. 209-226.

ILHA, Susie Enke; LARA, Claudia Camila; CÓRDOBA, Alexander Severo. A interface entre a fala e a escrita dos ditongos orais mediais [ej] e [ow] de sujeitos nos anos iniciais do ensino fundamental. Verba volant, v. 3, n. 2, p. 124-134, 2012. 
LIMA HENRIQUE, Pedro Felipe de; HORA, Dermeval da. Da fala à escrita: a monotongação de ditongos decrescentes na escrita de alunos do $3^{\circ}$ ao $5^{\circ}$ ano do ensino fundamental. Letrônica, v. 6, n. 1, p. 108-121, 2013.

LOPEZ, Barbara S. The sound pattern of Brazilian Portuguese (Cariocan dialect). Tese (Doutorado, PhD). Los Angeles: University of California, 1979.

MASSINI-CAGLIARI, Gladis. Ditongos e hiatos em português arcaico: uma abordagem otimalista. Letras de Hoje, v. 38, n. 4, p. 319-338, 2003.

MATTOS E SILVA, Rosa Virgínia. O português são dois. São Paulo: Parábola, 2004.

MOLliCA, Maria Cecília. Influência da fala na alfabetização. Rio de Janeiro: Tempo Brasileiro, 2000.

MONARETTO, Valeria N. de 0. O status fonológico da vibrante. Letras de Hoje, v. 29, n. 4, p.153-157, 1994.

PAIVA, Maria da Conceição Auxiliadora de. Supressão das semivogais nos ditongos decrescentes. In: OLIVEIRA E SILVA, Giselle Machline de; SCHERRE, Maria Marta Pereira (orgs.) Padrões sociolinguísticos. Rio de Janeiro: Tempo Brasileiro, 1996a. p. 217-236.

PAIVA, Maria da Conceição Auxiliadora de. Atuação das variáveis sociais na supressão das semivogais anteriores nos ditongos decrescentes. In: OLIVEIRA E SILVA, Giselle Machline de; SCHERRE, Maria Marta Pereira (orgs.) Padrões sociolinguísticos. Rio de Janeiro: Tempo Brasileiro, 1996b. p. 325-333.

PAIVA, Maria da Conceição de. A variável gênero/sexo. In: MOLLICA, Maria Cecilia; BRAGA, Maria Luiza. Introdução à sociolinguística. São Paulo: Contexto, 2010. p. 33-42.

ROSENTHALL, Sam. The distribution of prevocalic vowels. Natural Language and Linguistic Theory, v. 15, p. 139-180, 1997.

SELKIRK, Elisabeth. The syllable. In: HULST, Harry; SMITH, Van Der (Ed.) The structure of phonological representations (part. II). Dordrecht: Foris, 1982. p. 337-383.

SIMIONI, Taíse. A variação entre ditongo crescente e hiato em Porto Alegre (RS). Todas as letras, v. 10, n. 1, p. 130-138, 2008.

Recebido em junho de 2014.

Aceito em outubro de 2014. 